Check for updates

Cite this: RSC Adv., 2019, 9, 12877

Received 15th February 2019

Accepted 21st April 2019

DOI: 10.1039/c9ra01164a

rsc.li/rsc-advances

\section{Three-dimensional "skin-framework" hybrid network as electroactive material platform for high-performance solid-state asymmetric supercapacitor $\dagger$}

\author{
Liaoyuan Xia, (D)*ab Shaoheng Hu, ${ }^{\text {ab }}$ Xueqin Zhang, ${ }^{\text {ab }}$ Le Huang, $^{\text {ab }}$ Yu Liao, ${ }^{\text {ab }}$ \\ Yan Qing, ${ }^{a}$ Yiqiang Wu, ${ }^{* a}$ Wenping Jiang ${ }^{a}$ and Xihong Lu (DD *c
}

Three-dimensional (3D) electrode materials are ideal candidates for use in fabricating high-performance supercapacitors (SCs), owing to their unique network structure and excellent electrochemical properties. In this study, an aerogel film produced by the freeze-drying self-aggregation of multiwall carbon nanotubes (MWCNTs) and cellulose nanofibers (CNFs) served as the "skin", and an inter-connected 3D network of nickel foam (NF) as the "framework", for the fabrication of an MWCNT/CNF-NF (called MCN) hybrid material with a distinct "skin-framework" architecture. Considering the metrics of excellent conductivity, high wettability, binder-free and unique 3D "skin-framework" structure, the MCN hybrid material has great potential as an electroactive material platform in constructing state-of-the-art asymmetric supercapacitor (ASC) electrodes. By incorporating MCN with electroactive manganese dioxide $\left(\mathrm{MnO}_{2}\right)$ and active carbon ( $\left.\mathrm{AC}\right), \mathrm{MnO}_{2}-\mathrm{MCN}$ and $\mathrm{AC}-\mathrm{MCN}$ composite electrodes with respective high areal capacitances of 1784.8 (equal to $469.7 \mathrm{~F} \mathrm{~g}^{-1}$ ) and $868.8 \mathrm{mF} \mathrm{cm}^{-2}$ (equal to $126.3 \mathrm{~F} \mathrm{~g}^{-1}$ ) at 5 $\mathrm{mA} \mathrm{cm}{ }^{-2}$ were successfully prepared. Further, both kinds of electrodes exhibited high charge/discharge ability rates and good cycle performance. Moreover, an optimally assembled $\mathrm{MnO}_{2}-\mathrm{MCN} / \mathrm{AC}-\mathrm{MCN}$ solid-state ASC was reversibly charged/discharged at voltages as high as $1.8 \mathrm{~V}$ and possessed a remarkable volumetric capacity of $9.83 \mathrm{~F} \mathrm{~cm}^{-3}$ and an energy density of $4.25 \mathrm{~mW} \mathrm{~h} \mathrm{~cm}$, as well as good cycle stability.

\section{Introduction}

The rapid development of portable electronics has induced a demand for high-energy-density and lightweight energy storage devices. ${ }^{1-6}$ Solid-state asymmetric supercapacitors (ASCs), which are a new type of energy storage device, are assembled from positive and negative electrodes of different voltage windows. ${ }^{7-12}$ They are capable of operation over a wider voltage range, resulting in higher energy and power densities. These remarkable characteristics make them very attractive as ideal energy storage devices for portable electronics. Unlike traditional supercapacitors, a solid-state ASC is typically

${ }^{a}$ College of Material Science and Engineering, Central South University of Forestry and Technology, Changsha 410004, P. R. China.E-mail:wuyq0506@126.com

${ }^{b}$ Hunan Province Key Laboratory of Materials Surface \& Interface Science and Technology, Central South University of Forestry and Technology, Changsha 410004, P. R. China.E-mail: xly1516@126.com

${ }^{c} M O E$ of the Key Laboratory of Bioinorganic and Synthetic Chemistry, School of Chemistry, Sun Yat-Sen University, Guangzhou 510275, P. R. China. E-mail: luxh6@mail.sysu.edu.cn

$\dagger$ Electronic supplementary information (ESI) available. See DOI: 10.1039/c9ra01164a composed of positive and negative electrodes and a gel electrolyte. Among these components, the performance of the electrodes is very critical to the overall performance of the ASC. Considerable effort has thus been invested in the development of high-performance positive and negative electrodes in solidstate ASCs. ${ }^{13-19}$

Among the different electrode materials that have been recently developed for the fabrication of solid-state supercapacitors, those with unique 3D nanostructures have been found to be very promising, with the nanostructures providing large interfaces for ion diffusion and charge transport. ${ }^{\mathbf{2 0 - 2 4}}$ Nickel foam (NF) has particularly attracted much attention because of its usability as a substrate/current collector and a template for preparing $3 \mathrm{D}$ electrodes. ${ }^{25-30}$ The highly porous $3 \mathrm{D}$ structure of NF and the large electrode-electrolyte interface imbue it with improved electrolyte impregnation and reduced ion diffusion distance. In addition, the high conductivity and good mechanical strength of NF make it an ideal current collector for a supercapacitor. Encouraged by these advantages, designers have put considerable effort into the utilization of NF in $3 \mathrm{D}$ electrodes. $^{31-33}$ The material has been used as the template for the development of a number of $3 \mathrm{D}$ electrodes with 
excellent electrochemical properties, through methods such as hydrothermal reaction, electrochemical synthesis, and chemical vapor deposition (CVD). ${ }^{34-37}$ However, the fabrication processes involve many complex steps, rigorous conditions, and the use of expensive equipment, which have severely impeded the practical application of such electrodes. Furthermore, these methods involve only the deposition or growing of the substances on the NF frameworks and do not favor the uniform distribution of the substances nor enhance their loading capacity owing to the limited specific surface area and poor versatility of NF. Therefore, the use of NF for the simple and scalable fabrication of high-performance $3 \mathrm{D}$ electrodes remains a significant challenge.

In this work, we propose a simple, effective, and generally applicable method to rationally design and fabricate advanced 3D electrodes. Unlike conventional methods for producing 3D electrodes by chemical vapor deposition or hydrothermal reaction using an NF template/substrate, the method utilizes an MCN with a 3D "skin-framework" network as the electroactive material platform. On the one hand, NF is used as a skeletal support and affords the electrodes good mechanical properties and superb electrical conductivity. On the other hand, CNF is not only used to facilitate the uniform dispersion of untreated MWCNT but favors the formation of a stable MWCNT/CNF "skin", thus guaranteeing the introduction of active materials. Consequently, the obtained $\mathrm{MnO}_{2}$-MCN and AC-MCN electrodes not only possess a high areal capacity, but also an outstanding discharge rate and low AC impedance. Moreover, an as-fabricated $\mathrm{MnO}_{2}-\mathrm{MCN} / / \mathrm{AC}-\mathrm{MCN}$ solid-state ASC device developed with such electrodes can be reversibly charged/ discharged at high voltages of up to $1.8 \mathrm{~V}$ and has very good high-volume energy and power densities and excellent discharge and cycle performance. Therefore, this work provides a promising strategy for the rational design and fabrication of high-performance 3D electrodes for potential application in portable electronic devices.

\section{Materials and method}

\subsection{Chemicals and materials}

All the regents and materials used in this work were used as received without further purification. The CNFs were prepared using our previously described method with minor modifications. MWCNTs (TNIM2, d8-15 nm) were purchased from the Chengdu Institute of Organic Chemistry. AC was supplied by Fujian Xinsen Carbon Limited. Nickel foam was supplied by Changsha Lyrun Material Co., Ltd. Sodium sulfate $\left(\mathrm{Na}_{2} \mathrm{SO}_{4}\right)$, polyvinyl alcohol (PVA), lithium chloride ( $\mathrm{LiCl})$, potassium permanganate $\left(\mathrm{KMnO}_{4}\right)$, hydrochloric acid $(\mathrm{HCl})$, and anhydrous ethanol were obtained from the Sinopharm Chemical Reagent Company. Deionized water was used as prepared.

\subsection{Preparation of 3D network of MCN and MN hybrid materials}

The typical preparation procedure was as follows. Commercial $\mathrm{NF}$ measuring $16.0 \mathrm{~cm} \times 13.5 \mathrm{~cm}$ was soaked in acetone and ethanol for $6 \mathrm{~h}$ and then washed several times with deionized water. It was then dried in a vacuum at $60{ }^{\circ} \mathrm{C}$ and weighed, with the weight denoted by $W_{0}$. The pretreated NF was subsequently immersed in a homogeneously dispersed solution of MWCNT and $\mathrm{CNF}(\mathrm{wt} \%=0.5 \%)$ with a mass ratio of $1.5: 1$. After a specified time, the NF was removed from the solution and frozen for $24 \mathrm{~h}$ in a freeze-dryer at $-50{ }^{\circ} \mathrm{C}$ and then vacuum dried at 4.5 Pa for 3 days. This soaking and freeze-drying cycle was repeated 3-5 times, after which the final weight of the NF was taken, with the result denoted by $W_{1}$. The loading capacity of the MWCNT/CNF per unit area of MCN was then calculated as $\left(W_{1}-W_{0}\right) / S_{\mathrm{NF}}$, where $S_{\mathrm{NF}}$ is the area of the NF. The unit area loading capacity was determined to be $5.6 \mathrm{mg} \mathrm{cm}^{-2}$.

In order to demonstrate the importance of CNF for the dispersion of MWCNTs and the structural stability of MWCNT/ CNF aerogel films, we have prepared MN hybrid materials using the same procedure as MCN. Except for impregnation of MN with ultrasonically dispersed MWCNT solution $(\mathrm{wt} \%=0.5 \%)$.

\subsection{Preparation of the $\mathrm{MnO}_{2}-\mathrm{MCN}$ and AC-MCN 3D electrodes}

(1) The preparation of the $\mathrm{MnO}_{2}-\mathrm{MCN}$ electrode was typically as follows. An MCN measuring $6 \mathrm{~cm} \times 6 \mathrm{~cm}$ was used as the platform for loading the $\mathrm{MnO}_{2}$ electroactive material to match the AC-MCN negative electrode. Based on our previous work, ${ }^{24}$ the $\mathrm{MnO}_{2}$-MCN positive electrodes were prepared using different reaction times $(4,5,6$, and $7 \mathrm{~h})$ and the optimum time was determined for $6 \mathrm{~h}$ (Fig. S1 $\dagger$ ). All the samples were washed using ethanol and deionized water in turn and then vacuum dried at $60{ }^{\circ} \mathrm{C}$. They were subsequently subjected to heat treatment at $220{ }^{\circ} \mathrm{C}$ for $2 \mathrm{~h}$.

(2) The preparation of the AC-MCN electrode was typically as follows. Firstly, the pretreated and weighed NF (denoted by $W_{0}$ ) was immersed in a homogeneously dispersed solution of MWCNT, $\mathrm{CNF}$, and AC (wt $\%=1.43 \%)$ with a mass ratio of $1: 1: 8$ for a certain time. Then, the NF was removed from the solution, frozen for $24 \mathrm{~h}$ in a freeze-dryer at $-50{ }^{\circ} \mathrm{C}$, and then vacuum dried at 4.5 Pa for 3 days. This soaking and freezedrying cycle was repeated 4-6 times, after which the final weight of the NF was taken, with the result denoted by $W_{2}$. The loading capacity of the MWCNT/CNF/AC per unit area of MCN was then calculated as $\left(W_{2}-W_{0}\right) / S_{\mathrm{NF}}$, where $S_{\mathrm{NF}}$ is the area of the NF. The mass per unit area of the load AC was determined to be $6.88 \mathrm{mg} \mathrm{cm}^{-2}$.

\subsection{Materials characterization}

Scanning electron microscopy (SEM, MIRA3) and transmission electron microscopy (TEM, JEM-2100F) were used for the morphological and microstructural characterization of the electrode materials and electrode sheets. X-ray photoelectron spectrometry (XPS) (Escalab 250Xi, Thermo Fisher Scientific) was used to analyze the chemical composition and element valence state of the electrode surfaces, while atomic absorption spectrometry (ICE3000, Thermo Fisher Scientific) was used to evaluate the loading of $\mathrm{MnO}_{2}$ unto the electrode. The contact angles of $\mathrm{Na}_{2} \mathrm{SO}_{4}$ electrolyte $(1 \mathrm{M})$ drops on the surface of the 
electrode sheets were measured at $25{ }^{\circ} \mathrm{C}$ using a contact angle meter (SL150). Nitrogen gas adsorption was measured using a Micromeritics ASAP $2020 \mathrm{M}$ analyzer at $77 \mathrm{~K}$, with all the samples degassed at $150{ }^{\circ} \mathrm{C}$ in a vacuum for $8 \mathrm{~h}$.

\subsection{Electrochemical measurements}

An electrochemical workstation (CHI 660E) was used to perform electrochemical tests on the electrodes and other components. The electrochemical testing of the electrodes was conducted using a three-electrode system with a $1 \mathrm{M} \mathrm{Na}_{2} \mathrm{SO}_{4}$ solution electrolyte, platinum plate counter electrode, and saturated calomel reference electrode. The working electrode had an effective area of $1.0 \mathrm{~cm} \times 1.0 \mathrm{~cm}$. The voltage window of the positive electrode was $0-0.8 \mathrm{~V}$, while that of the negative electrode was -1 to $0 \mathrm{~V}$. To fabricate a solid-state ASC, a LiCl/PVA gel electrolyte was prepared by adding LiCl ( $4.24 \mathrm{~g}$ ) and PVA ( $2 \mathrm{~g}$ ) into deionized water $(20 \mathrm{~mL})$ and heating at $85{ }^{\circ} \mathrm{C}$ for $1 \mathrm{~h}$ under constant stirring. Two pieces of each of the produced AC-MCN and $\mathrm{MnO}_{2}$ MCN electrodes were immersed into the LiCl/PVA solution for $30 \mathrm{~min}$, and then taken out and assembled together with a cellulose separator sandwiched in between them. Upon completion, the assembly was dried for $1 \mathrm{~h}$ at $40{ }^{\circ} \mathrm{C}$ and packaged with polyester (PET) film to prevent contamination of the device during the electrochemical characterization testing process.

\section{Results and discussion}

Fig. 1a illustrates the preparation of the $3 \mathrm{D} \mathrm{MnO}_{2}-\mathrm{MCN}$ and ACMCN electrodes. As shown in Fig. 1a, the MWCNT/CNF solution is first introduced into the 3D NF network (Fig. 1b) by a simple pouring process. Due to the fact that CNF easily forms films, the self-assembled MWCNT/CNF aerogel film formed during freezedrying was thus randomly stacked onto the NF-network (Fig. 1d) to form the 3D-network "skin-framework" structure of the MCN hybrid material. Benefiting from the high specific surface area and versatility of MWCNT (such as its ability to combine with the metal oxide $\mathrm{MnO}_{2}$ and conductive polymer PPy to improve their discharge rate ${ }^{38,39}$ ), CNF has excellent electrolyte adsorption and MWCNT dispersion ability, and NF possesses high electrical conductivity and mechanical strength. Therefore, the large-scale MCN obtained (see Fig. S2 $\dagger$ ) is promising for use as an electroactive platform for fabrication of high-performance 3D electrodes. Furthermore, the MCN electrode sheet exhibits good flexibility and bending performance (Fig. 1f). In addition, benefiting from the advantages of the MCN platform, we have successfully prepared a high-performance AC-MCN electrode using a similar strategy.

To demonstrate the advantages of MCN as an electroactive material platform, its microstructure and morphology were characterized by SEM and TEM. As shown in Fig. 1b, NF has an inter-connected 3D network, which affords MCN a unique 3D porous "skin-framework" structure in which the 3D NF network constitutes the "framework" and the MWCNT/CNF aerogel film is the "skin" (Fig. 1d). This unique structure significantly enhances the conductivity and specific surface area of the MCN platform because the MWCNTs are not only a carrier for electroactive materials (such as $\mathrm{MnO}_{2}$ ) but also act as a conductive agent. In fact, the $\mathrm{N}_{2}$ adsorption-desorption measurement

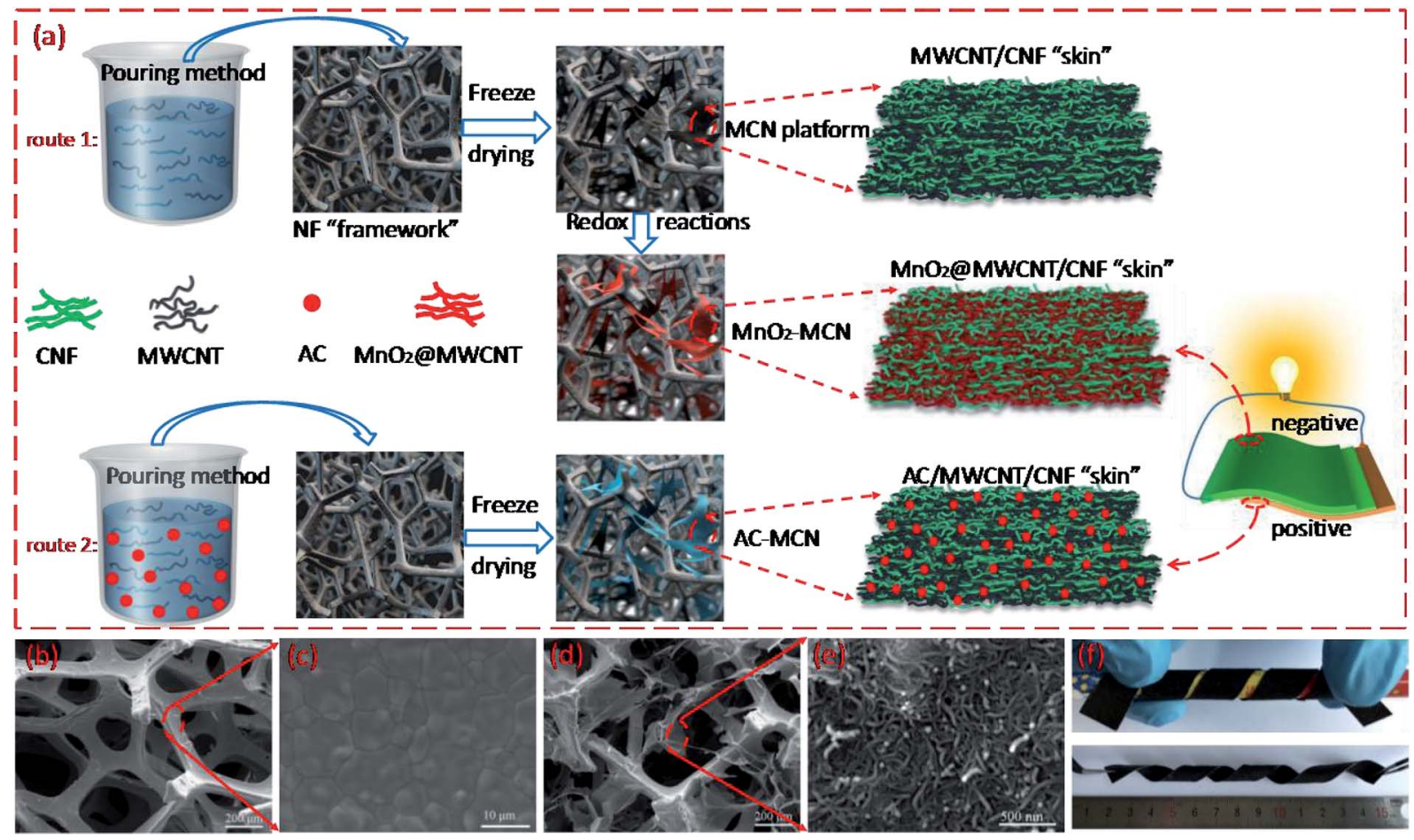

Fig. 1 (a) Illustration of the preparation of the $\mathrm{MnO}_{2}-\mathrm{MCN}$ (route 1) and AC-MCN (route 2) electrodes, and construction of the solid-state ASC device; SEM images of the ( $b$ and $c) N F$ and ( $d$ and e) MCN hybrid material with different magnifications; and ( $f$ ) demonstration of the flexibility and bending properties of the $\mathrm{MCN}$ electrode sheet. 
showed that the specific surface area of MCN was much larger than NF (Fig. S3†). To demonstrate the scalability of MCN as an electroactive platform for the fabrication of high-performance electrodes, $\mathrm{MnO}_{2}-\mathrm{MCN}$ electrodes were produced by redox reactions $\left(4 \mathrm{MnO}_{4}{ }^{-}+3 \mathrm{C}+\mathrm{H}_{2} \mathrm{O} \rightarrow 4 \mathrm{MnO}_{2}+\mathrm{CO}_{3}{ }^{2-}+2 \mathrm{HCO}_{3}{ }^{-}\right) .^{40}$ As shown in Fig. 2a and b, the $\mathrm{MnO}_{2} @ M W C N T / C N F$ "skin" is still entirely stacked onto the 3D "framework" of NF after redox reaction with $\mathrm{KMnO}_{4}$ solution. Moreover, a rougher surface loaded with numerous nanoparticles can be observed in the network structure (Fig. 2c). These nanoparticles are assumed to be $\mathrm{MnO}_{2}$ formed in situ at the MWCNT surface during the redox process. In addition, Fig. $2 \mathrm{~g}$ and $\mathrm{h}$ show that $\mathrm{MnO}_{2}$ nanoparticles ranging between 3 and $5 \mathrm{~nm}$ are loaded onto the MWCNT surface. To further demonstrate the scalability of MCN as an electroactive platform for the construction of highperformance electrodes, the AC-MCN electrode is prepared by a similar strategy (route 2). As shown in Fig. 2d and e, the AC particles are uniformly distributed in the MWCNT/CNF aerogel film. The high-magnification SEM image illustrates that the MWCNT and CNF were tightly wound on the surface of the AC particles (Fig. 2f, indicated by an arrow), providing an effective pathway for electron transport and ion diffusion in the AC electroactive materials. These results show that, compared with $\mathrm{NF}$, the use of MCN as a platform for electroactive materials is more broadly applicable and offers several structural advantages for the fabrication of high-performance 3D electrodes.

As stated above, the unique 3D porous "skin-framework" network of MCN is the key to its role as a platform for electroactivity materials. This is because the homogeneously distributed untreated MWCNT in the MWCNT/CNF aerogel film is the carrier and conductive pathway of the active materials $\mathrm{MnO}_{2}$ and AC. Hence, the dispersibility of the MWCNT and the structural stability of the MWCNT/CNF "skin" directly affect the performance of MCN as an electroactive platform for fabrication of 3D electrodes. To demonstrate the importance of CNF for the two aforementioned factors, we compared the microstructure and structural stability of the MCN platform and
MWCNT-NF hybrid materials (denoted as MN). As shown in Fig. 3a and b, the MWCNT/CNF "skin" of the MCN platform well maintains its thin film morphology before and after ultrasonic treatment in ethanol and water mixed solution, indicating excellent structural stability. Conversely, the MWCNT in MN hybrid barely forms a large-scale and film-like "skin" (Fig. 3c) and has poor structural stability. After ultrasonic treatment, the film-like "skin" obviously peels off from the NF framework (Fig. 3d). The desirable performance of MCN is because CNF not only evenly distributes untreated MWCNT, but its excellent filmforming property is also beneficial to MWCNT/CNF selfassembly to form a structurally stable aerogel film. ${ }^{41}$ However, without the auxiliary dispersion of CNF, it is difficult to uniformly disperse untreated MWCNT in a water solution, much less achieve the formation of a stable films on the 3D network of NF during freeze-drying. Moreover, after 10 minutes of ultrasound treatment for the MCN sheet, its solution remained clear and transparent (Fig. 3e, Video $\mathrm{S} 1 \dagger$ ), whereas after only 1 minute of ultrasound treatment for the MN sheet, its solution turned black (Fig. 3f, Video S1†) owing to the falling off MWCNT from the NF framework. This further demonstrates the superior structural stability of the MWCNT/CNF "skin" stacked onto the MCN platform. In addition, it is worth noting that CNF also effectively improves the wettability of the $\mathrm{MnO}_{2}$ MCN and AC-MCN electrodes (Fig. 3g, Video S2 $\dagger$ ), thereby facilitating rapid diffusion of the electrolyte and improving the performance of the electrodes.

To further elucidate the advantages of MCN in terms of its microstructure, the porous structures of $\mathrm{NF}, \mathrm{MCN}$, and $\mathrm{MnO}_{2}$ MCN were analyzed by $\mathrm{N}_{2}$ adsorption. As shown in Fig. $3 \mathrm{~h}, \mathrm{NF}$ has an atypical type II adsorption-desorption curve. Conversely, those of $\mathrm{MCN}$ and $\mathrm{MnO}_{2}-\mathrm{MCN}$ hybrids are combinations of type I and type IV, indicating the presence of micropores and mesopores. ${ }^{42}$ In addition, the adsorption-desorption isotherms of $\mathrm{MCN}$ and $\mathrm{MnO}_{2}-\mathrm{MCN}$ have a $\mathrm{H} 3$ hysteresis loop at relative pressures of $0.8-1.0$, suggesting the existence of macropores. ${ }^{43}$ The inset of Fig. 3h shows the corresponding pore size
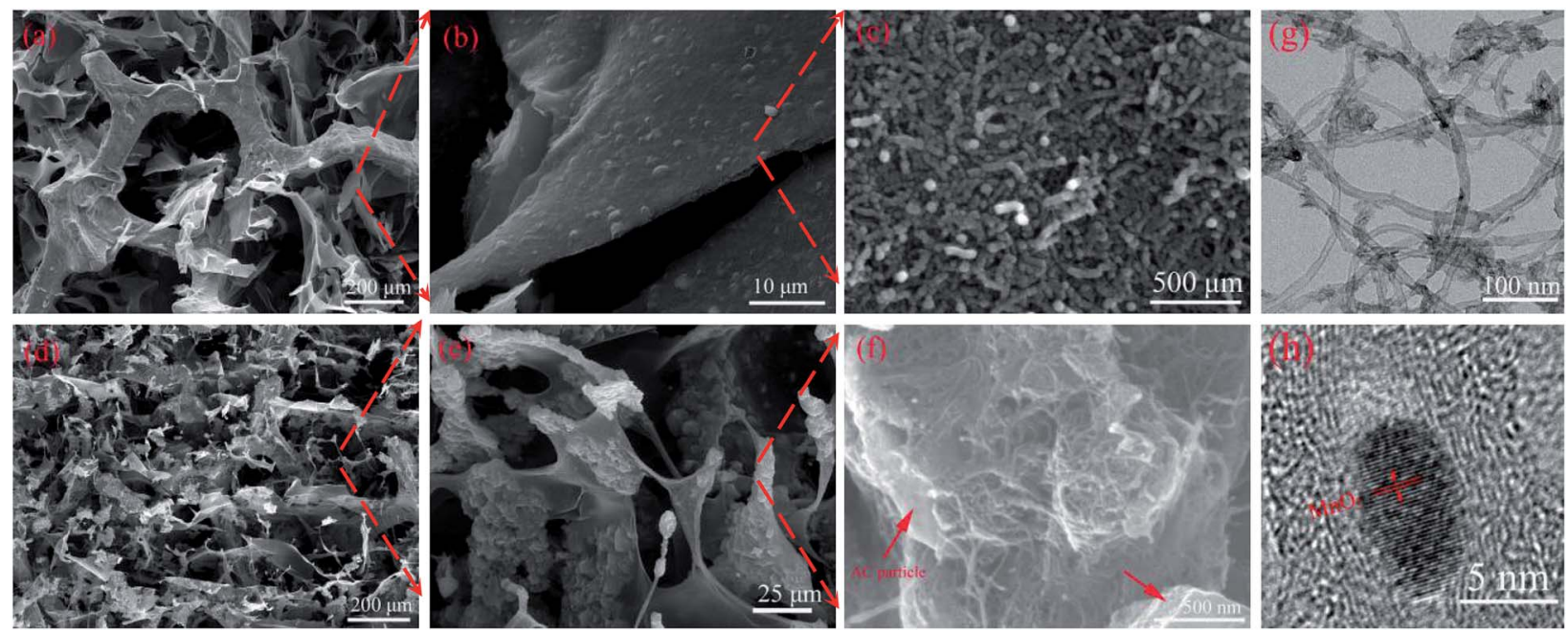

Fig. $2 \mathrm{SEM}$ images of $(\mathrm{a}-\mathrm{c}) \mathrm{MnO}_{2}-\mathrm{MCN}$, (d-f) $\mathrm{AC}-\mathrm{MCN}$ electrodes with different magnifications; and $\mathrm{TEM}$ images of ( $\mathrm{g}$ and $\mathrm{h}$ ) $\mathrm{MnO} \mathrm{O}_{2}-\mathrm{MCN}$ electrode with different magnifications. 

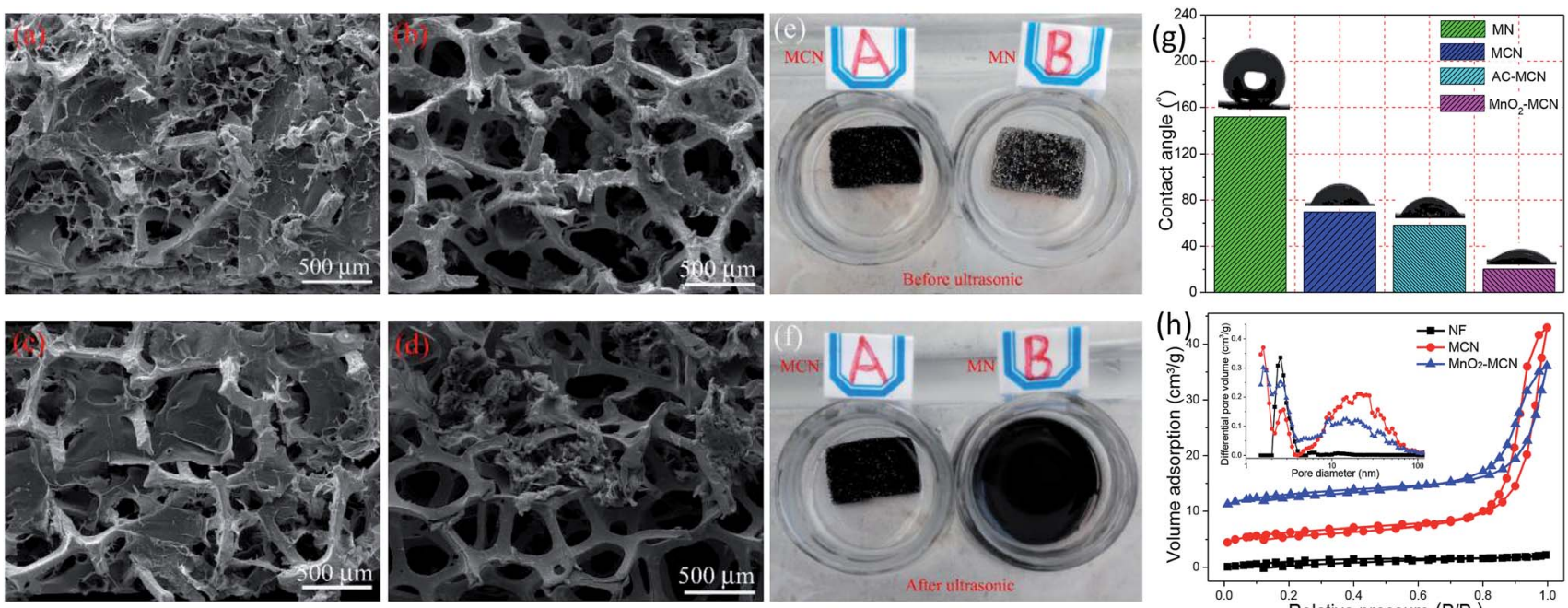

Fig. 3 SEM images of MCN (a) before and (c) after ultrasonic treatment; SEM images of MN (b) before and (d) after ultrasonic treatment; digital pictures of $M C N$ sheet $(1 \mathrm{~cm} \times 1.5 \mathrm{~cm})$ and $M N$ sheet $(1 \mathrm{~cm} \times 1.5 \mathrm{~cm})$ (e) before and (f) after ultrasonic treatment in ethanol and water mixed solution; (g) histogram and corresponding digital photos (inset) of the contact angle of the $M N, M C N, A C-M C N$ and $M n O_{2}-M C N$ electrode materials; and (h) $\mathrm{N}_{2}$ adsorption-desorption isotherm of $\mathrm{NF}, \mathrm{MCN}$, and $\mathrm{MnO}_{2}-\mathrm{MCN}$ and their corresponding DFT pore size distribution (inset).

distribution (PSD) curves of NF, MCN, and $\mathrm{MnO}_{2}-\mathrm{MCN}$ obtained by the density functional theory (DFT). A characteristic peak can be observed at $2.5 \mathrm{~nm}$ for all the samples, primarily due to the cracks present on the NF surfaces (Fig. 1c). Conversely, MCN and $\mathrm{MnO}_{2}-\mathrm{MCN}$ have a sharp characteristic peak at $1.6 \mathrm{~nm}$, possibly due to the pores formed by the uniform distribution of MWCNT and CNF (Fig. 1e and 2c). The two materials also have multiple broad characteristic peaks between 9.3 and $34.3 \mathrm{~nm}$, mainly attributed to random pores of various sizes in MCN due to the MWCNT/CNF thin-film stacking. It should be noted that macropores are not reflected in a PSD curves, although they can be verified by SEM observation (Fig. 1d and 2a). These results confirm the higher specific surface area and beneficial porous structure of MCN that enhance its use as an active material platform for the fabrication of high-performance electrodes.

XPS and EDS were used to determine the composition and chemical state of the $\mathrm{MnO}_{2}$-MCN electrode. Fig. $\mathrm{S} 4 \dagger$ and 4 show the full XPS spectrum of the $\mathrm{MnO}_{2}$-MCN electrode and the corresponding Mn 2p and O 1s XPS spectra, respectively. The spectra confirm the presence of manganese oxide in the electrode. Fig. 4a reveals two characteristic peaks of Mn 2p at 653.09 and $642.39 \mathrm{eV}$, which are identical with those of $\mathrm{Mn} 2 \mathrm{p}_{1 / 2}$ and Mn $2 \mathrm{p}_{3 / 2}$ reported for $\mathrm{Mn}^{4+}$ in the literature. ${ }^{44,45}$ This indicates the predominant occurrence of $\mathrm{Mn}$ as $\mathrm{Mn}^{4+}$ in the electrode. The three characteristic peaks at 533.6, 531.9, and $530.2 \mathrm{eV}$ in the fitted $\mathrm{O} 1 \mathrm{~s}$ spectra (Fig. 4b) correspond to $\mathrm{Mn}-\mathrm{O}, \mathrm{Mn}-\mathrm{OH}$, and $\mathrm{H}-\mathrm{O}-\mathrm{H}$, respectively. This agrees well with the literature ${ }^{46,47}$ and proves that $\mathrm{MnO}_{2}$ is loading on the $\mathrm{MnO}_{2}$ - $\mathrm{MCN}$ electrode after the redox reaction process. Fig. $4 \mathrm{c}$ shows the distributions of $\mathrm{Mn}$ and $\mathrm{O}$ in the $\mathrm{MnO}_{2}$-MCN electrode, as determined by EDS. It can be seen that both elements are uniformly distributed in the electrode, further proving the even loading of nano$\mathrm{MnO}_{2}$ formed in situ by redox processes when MCN is used as the electroactive material platform.
To prove the suitability of MCN for the fabrication of highperformance electrodes, a $\mathrm{MnO}_{2}-\mathrm{MCN}$ electrode was successfully prepared by redox reaction using MCN as the platform. Fig. 5a compares the cyclic voltammogram (CV) curves of the $\mathrm{MCN}$ and $\mathrm{MnO}_{2}-\mathrm{MCN}$ electrodes for a scanning rate of $100 \mathrm{mV}$ $\mathrm{s}^{-1}$. As expected, the $\mathrm{MnO}_{2}-\mathrm{MCN}$ electrode exhibits a higher current density than the MCN electrode, its capacitance being mainly due to the loaded nano- $\mathrm{MnO}_{2}$. Further, the galvanostatic charge/discharge (GCD) curves of the two electrodes for a current density of $5 \mathrm{~mA} \mathrm{~cm}^{-2}$ (Fig. S5a†) clearly shows that the $\mathrm{MnO}_{2}-\mathrm{MCN}$ electrode has a longer discharge time, further substantiating its excellent capacitive properties. The CV curve of the $\mathrm{MnO}_{2}-\mathrm{MCN}$ electrode also preserves its quasi-rectangular shape for scanning rates of $5-100 \mathrm{mV} \mathrm{s}^{-1}$ (Fig. 5b), suggesting ideal capacitive characteristics and outstanding discharge performance of the electrode.
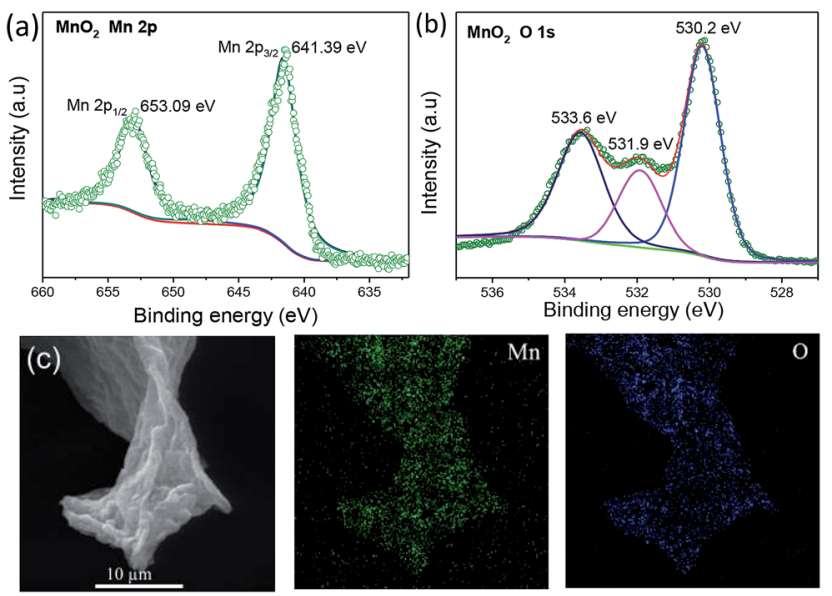

Fig. 4 XPS spectra and peak fitting of the $\mathrm{MnO}_{2}-\mathrm{MCN}$ electrode (a) $\mathrm{Mn}$ and (b) $\mathrm{O}$, and (c) EDS maps of $\mathrm{Mn}$ and $\mathrm{O}$ for the $\mathrm{MnO}_{2}-\mathrm{MCN}$ electrode. 

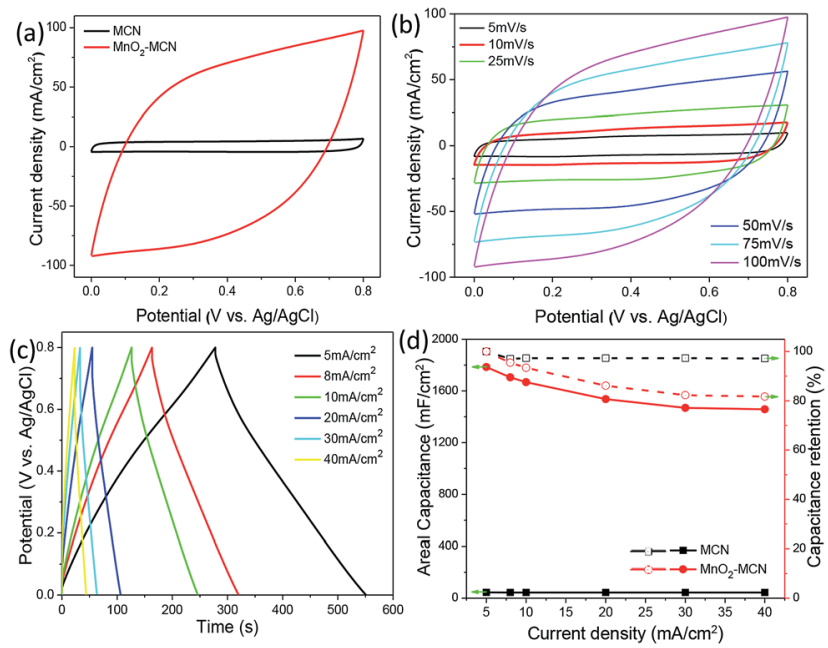

Fig. 5 (a) $\mathrm{CV}$ curves of the $\mathrm{MCN}$ and $\mathrm{MnO}_{2}-\mathrm{MCN}$ electrodes obtained using a scanning rate of $100 \mathrm{mV} \mathrm{s}^{-1}$; (b) CV curves of the $\mathrm{MnO}_{2}-\mathrm{MCN}$ electrode for scanning rates of $5-100 \mathrm{mV} \mathrm{s}^{-1}$; (c) GCD curves of the $\mathrm{MnO}_{2}-\mathrm{MCN}$ electrode for current densities of 5-40 $\mathrm{mA} \mathrm{cm}^{-2}$; and (d) areal capacitance and capacitance retention rate of the $M C N$ and $\mathrm{MnO}_{2}-\mathrm{MCN}$ electrodes as functions of the current density.

As shown in Fig. 5c, the GCD curves of the $\mathrm{MnO}_{2}-\mathrm{MCN}$ electrode for different current densities all have a symmetrical and triangular shape, revealing a good capacitive behavior and reversible charging-discharging. Fig. 5d shows the relationships between the areal capacity and capacity retention of the MCN and $\mathrm{MnO}_{2}$-MCN electrodes and the discharge current density. The areal capacity of the $\mathrm{MnO}_{2}-\mathrm{MCN}$ electrode of $1784.8 \mathrm{mF} \mathrm{cm}^{-2}$ (equal to $469.7 \mathrm{~F} \mathrm{~g}^{-1}$ ) at a current density of 5 $\mathrm{mA} \mathrm{cm}{ }^{-2}$ is obviously much higher than that of the MCN electrode, indicating a much higher discharge performance of the former. The capacity retention of the $\mathrm{MnO}_{2}-\mathrm{MCN}$ electrode is also as high as $81.7 \%$ at a current density of $40 \mathrm{~mA} \mathrm{~cm}^{-2}$. This is mainly because the uniformly distributed MWCNT in the $\mathrm{MnO}_{2}$-MCN electrode functions as the $\mathrm{MnO}_{2}$ nanoparticles carrier and effectively improves the discharge performance by affording excellent electrical conductivity; ${ }^{24}$ furthermore, its high specific surface area also facilitates the even loading of $\mathrm{MnO}_{2}$ nanoparticles. From Nyquist impedance plots (Fig. S5b and $\mathrm{c}^{\dagger}$ ), both the $\mathrm{MCN}$ and $\mathrm{MnO}_{2}-\mathrm{MCN}$ electrodes were observed to have very small impedances $(\sim 1 \mathrm{ohm})$, attributable to the high conductivity of the $3 \mathrm{D}$ network of $\mathrm{NF}$. The $\mathrm{MnO}_{2}$ MCN electrode maintains $92.3 \%$ of its initial capacitance after 3000 charge/discharge cycles at a current density of $10 \mathrm{~mA} \mathrm{~cm}^{-2}$ (Fig. S5d $\dagger$ ), demonstrating its good cycle performance. These results provide further evidence of the extraordinary advantages of MCN as an electroactive material platform for fabrication of high-performance 3D electrodes.

To further evaluate the feasibility of the MCN platform for the fabrication of high-performance 3D electrodes, we prepared an AC-MCN electrode by a similar strategy to match the $\mathrm{MnO}_{2}$ MCN electrode to assemble a solid-state ASC. Fig. 6a shows CV curves of the MCN and AC-MCN electrodes collected at a scanning rate of $100 \mathrm{mV} \mathrm{s}^{-1}$. It can be clearly seen that the current density of the AC-MCN electrode is much higher than that of the MCN electrode. This reveals the superior electrochemical capacity of the AC-MCN electrode. The CV curve of the AC-MCN electrode (Fig. 6b) exhibits a symmetrical quasi-rectangular form when the scan rate increases from 5 to $100 \mathrm{mV} \mathrm{s}^{-1}$, suggesting that the electrode has ideal capacitive characteristics and outstanding discharge performance. Further, the GCD curves of the MCN and AC-MCN electrodes for a current density of $5 \mathrm{~mA} \mathrm{~cm} \mathrm{~cm}^{-2}$ (Fig. S6a $\dagger$ ) clearly show that the AC-MCN electrode has a longer discharge time, further substantiating its excellent capacitive properties.

Fig. 6c represents the GCD curves of the AC-MCN electrode collected at various current densities from 5 to $40 \mathrm{~mA} \mathrm{~cm}^{-2}$. All the GCD curves exhibit good symmetry, further confirming the good capacitive behavior of the AC-MCN electrode. Fig. 6d shows the relationships between the areal capacity and capacity retention rate of the AC-MCN electrode with the discharge current density. Both the areal capacity and discharge performance of the AC-MCN electrode for a given current density are clearly superior. For example, the areal capacity of the AC-MCN electrode for a current density of $5 \mathrm{~mA} \mathrm{~cm}{ }^{-2}$ is $868.8 \mathrm{mF} \mathrm{cm}^{-2}$ (equal to $126.3 \mathrm{~F} \mathrm{~g}^{-1}$ ), which is much higher than that of MCN $\left(53.4 \mathrm{mF} \mathrm{cm}^{-2}\right)$. It should also be noted that the capacity retention rate of the $\mathrm{AC}-\mathrm{MCN}$ electrode is as high as $74.3 \%$ at a current density of $40 \mathrm{~mA} \mathrm{~cm}{ }^{-2}$. In addition, the AC-MCN electrode exhibits good electrochemical durability (Fig. S6b $\dagger$ ); after 3000 charge-discharge cycles at a current density of $10 \mathrm{~mA}$ $\mathrm{cm}^{-2}$, the capacitance retention remains above $89.3 \%$. Furthermore, the AC impedance spectrum exhibits a low resistance ( $\sim 1 \mathrm{ohm}$ ) for this electrode (Fig. S6c and $\mathrm{d} \dagger$ ), again confirming that the $3 \mathrm{D} \mathrm{MCN}$ is an excellent platform for fabricating high-performance electrodes.

To assemble the solid-state ASC device, we used the $\mathrm{MnO}_{2}$ MCN as the positive electrode and AC-MCN as the negative electrode. Prior to assembly, it was necessary to consider the
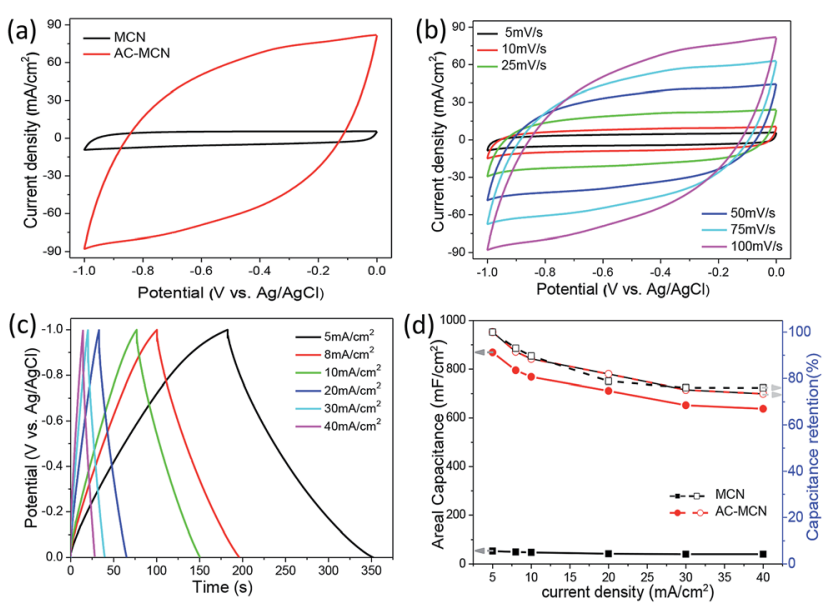

Fig. 6 (a) CV curves of the MCN and AC-MCN electrodes collected at a scanning rate of $100 \mathrm{mV} \mathrm{s}^{-1}$; (b) CV curves of the AC-MCN electrode for scanning rates of 5-100 $\mathrm{mV} \mathrm{s}^{-1}$; (c) GCD curves of the AC-MCN electrode for current densities of 5-40 $\mathrm{mA} \mathrm{cm} \mathrm{cm}^{-2}$; and (d) areal capacitance and capacitance retention rate of the MCN and AC-MCN electrodes as functions of the current density. 
charge balance between the anode and cathode during the assembly of the ASC. The balance can be described by the following equation: ${ }^{47}$

$$
C_{\mathrm{s}}^{+} \times \Delta V^{+} \times S^{+}=C_{\mathrm{s}}^{-} \times \Delta V^{-} \times S^{-}
$$

where $C_{\mathrm{s}}, \Delta V$, and $S$ are the areal capacity, potential window, and area of an electrode, respectively. Fig. 7a shows the CV curves of the AC-MCN cathode and $\mathrm{MnO}_{2}-\mathrm{MCN}$ anode obtained using a scanning rate of $50 \mathrm{mV} \mathrm{s}^{-1}$. Based on eqn (1), the ratio between the charges of the positive and negative electrodes was determined to be approximately $1: 1$. Using the stable potential windows of the AC-MCN and $\mathrm{MnO}_{2}-\mathrm{MCN}$ electrodes of -1.0 to $0.0 \mathrm{~V}$ and $0.0-0.8 \mathrm{~V}$, respectively (Fig. 7a), the operating voltage of the as-fabricated $\mathrm{MnO}_{2}-\mathrm{MCN} / / \mathrm{AC}-\mathrm{MCN}$ solid-state ASC was determined to be as high as $1.8 \mathrm{~V}$ (Fig. 7b). Fig. S7a† shows the $\mathrm{CV}$ curves of the ASC device for various scanning rates and a voltage window of $1.8 \mathrm{~V}$. All the curves can be observed to be symmetric and rectangle-like, indicative of good reaction reversibility and typical capacity characteristics of the ASC. This would enable the development of solid-state ASC devices with high energy densities.

Fig. 7c shows GCD curves of the $\mathrm{MnO}_{2}-\mathrm{MCN} / / \mathrm{AC}-\mathrm{MCN}$ ASC device for different current densities. The symmetrical and triangular shape curves demonstrate the outstanding capacity properties and rapid charging/discharging of the device. Fig. S7b $\dagger$ shows the GCD curves of the device for voltage windows of 1.0-1.8 $\mathrm{V}$ and a discharge current density of $10 \mathrm{~mA}$ $\mathrm{cm}^{-2}$. All the curves are roughly symmetrical and triangular, further confirming the ASC device as an ideal capacitor. As can be seen from Fig. 7d, the $\mathrm{MnO}_{2}-\mathrm{MCN} / / \mathrm{AC}-\mathrm{MCN}$ ASC device has its highest volumetric capacitance of $9.83 \mathrm{~F} \mathrm{~cm}^{-3}$ under a discharge current density of $5 \mathrm{~mA} \mathrm{~cm}^{-2}$ and voltage window of $1.8 \mathrm{~V}$, substantially higher than recently reported values for other ASCs such as a Ni/Co $\mathrm{NiO}_{4}-\mathrm{CP} / / \mathrm{Ni} / \mathrm{AC}-\mathrm{CP}-\mathrm{ASC}(4.48 \mathrm{~F}$ $\mathrm{cm}^{-3}$ at $\left.4 \mathrm{~mA} \mathrm{~cm}^{-2}\right),{ }^{48} \mathrm{PF} / \mathrm{Ni} / \mathrm{MnO}_{2} / / \mathrm{PF} / \mathrm{Ni} / \mathrm{AC}$ ASC $\left(1.4 \mathrm{~F} \mathrm{~cm}^{-3}\right.$ at $\left.2.5 \mathrm{~mA} \mathrm{~cm}^{-2}\right),{ }^{49} \mathrm{MnO}_{2} / / \mathrm{Ti}^{-} \mathrm{Fe}_{2} \mathrm{O}_{3} @ P E D O T$ ASC $\left(1.15 \mathrm{~F} \mathrm{~cm}^{-3}\right.$ at 1 $\left.\mathrm{mA} \mathrm{cm}{ }^{-2}\right),{ }^{50} \mathrm{MnO}_{2} / / \mathrm{Fe}_{2} \mathrm{O}_{3} \operatorname{ASC}\left(1.5 \mathrm{~F} \mathrm{~cm}^{-3}\right.$ at $\left.2 \mathrm{~mA} \mathrm{~cm}{ }^{-2}\right),{ }^{51}$ and $\mathrm{MnO}_{2} @ \mathrm{CNT} / / \mathrm{PPy} @ \mathrm{CNT}$ ASC $\left(2.2 \mathrm{~F} \mathrm{~cm}^{-3}\right.$ at $\left.2 \mathrm{~mA} \mathrm{~cm}^{-2}\right) .{ }^{52}$ When the current density increases from 5 to $40 \mathrm{~mA} \mathrm{~cm}^{-2}$, the capacity retention of the $\mathrm{MnO}_{2}$-MCN//AC-MCN ASC device is maintained as high as $75.4 \%$, validating its excellent discharge performance. This is mainly because the $\mathrm{MnO}_{2}-\mathrm{MCN}$ and AC-MCN electrodes consist of a unique multilayer structure (Fig. 7d and $\mathrm{S} 8 \dagger$ ), with the NF-formed 3D network conductive path between the multilayer structures also affording the electrodes excellent electrical conductivity. As can be seen from Fig. S7c, $\dagger$ the ASC retains $81.6 \%$ of its initial capacitance after 5000 charge/discharge cycles, revealing a good cycle performance. The electrochemical impedance spectra of the assembled ASC device were analyzed to evaluate the electrochemical behavior. As shown in Fig. 7e, the Nyquist impedance plot of the $\mathrm{MnO}_{2}$ MCN//AC-MCN ASC is almost parallel to the imaginary linear axis, once again indicating ideal capacitance properties of the device. The charge-transfer resistance is also very small $(\sim 1$ ohm), implying rapid charge transfer.

Fig. $7 f$ compares the volumetric power and energy density of the assembled $\mathrm{MnO}_{2}$-MCN//AC-MCN ASC device with those of other previously reported ASC devices. ${ }^{48-54}$ Notably, the present ASC exhibits a high energy density, high power density, and excellent discharge performance. For example, its volumetric energy is as high as $4.25 \mathrm{~mW} \mathrm{~h} \mathrm{~cm}^{-3}$ at a current density of $5 \mathrm{~mA}$
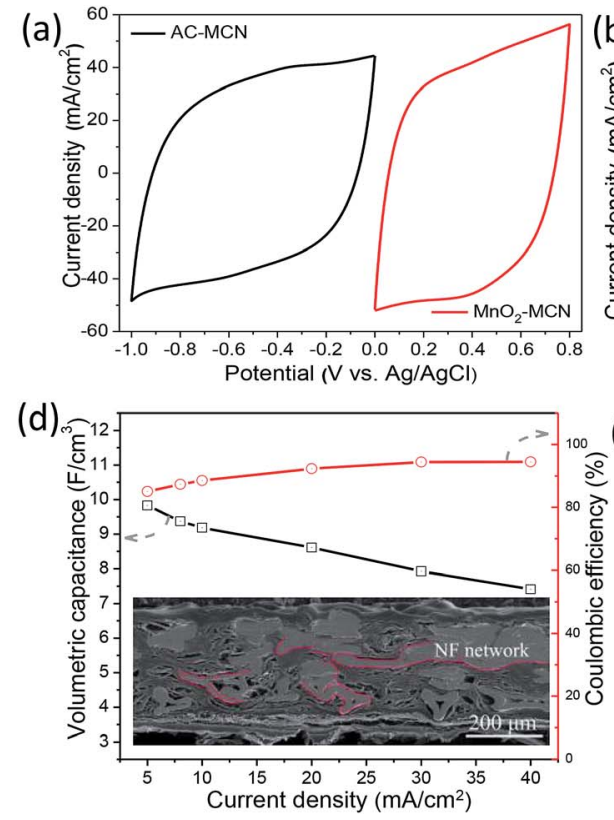
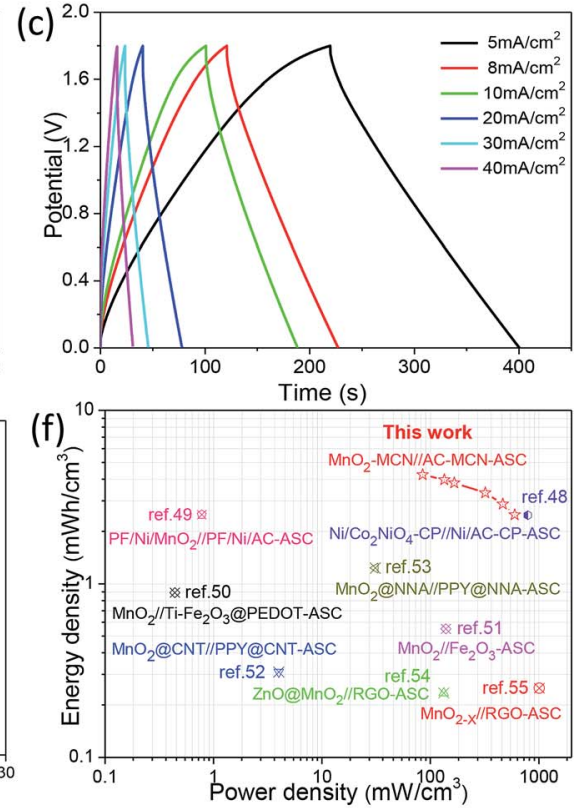

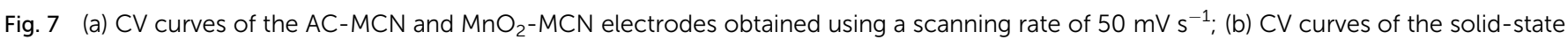
$\mathrm{MnO}_{2}-\mathrm{MCN} / / \mathrm{AC}-\mathrm{MCN}$ ASC device collected at a scanning rate of $50 \mathrm{mV} \mathrm{s}^{-1}$ and different voltage windows; (c) GCD curves of the ASC device for current densities of 5-40 mA cm${ }^{-2}$; (d) volumetric capacity and coulombic efficiency as a function of the current density, and (inset) crosssectional SEM image of the ASC device; (e) Nyquist plots of the ASC device; and (f) comparison of Ragone plots of the ASC device with those of other devices in the literature. ${ }^{48-55}$ 
$\mathrm{cm}^{-2}$, higher than those of many of the other ASC devices such as the $\mathrm{Ni} / \mathrm{Co}_{2} \mathrm{NiO}_{4}-\mathrm{CP} / / \mathrm{Ni} / \mathrm{AC}-\mathrm{CP}$ ASC $\left(2.48 \mathrm{~mW} \mathrm{~h} \mathrm{~cm}^{-3}\right.$ at $4 \mathrm{~mA}$ $\left.\mathrm{cm}^{-2}\right),{ }^{48} \mathrm{PF} / \mathrm{Ni} / \mathrm{MnO}_{2} / / \mathrm{PF} / \mathrm{Ni} / \mathrm{AC}$ ASC $\left(0.78 \mathrm{~mW} \mathrm{~h} \mathrm{~cm}^{-3}\right.$ at $2.5 \mathrm{~mA}$ $\left.\mathrm{cm}^{-2}\right),{ }^{49} \mathrm{MnO}_{2} / / \mathrm{Ti}-\mathrm{Fe}_{2} \mathrm{O}_{3}$ @PEDOT ASC $\left(0.89 \mathrm{~mW} \mathrm{~h} \mathrm{~cm}^{-3}\right.$ at 1 $\left.\mathrm{mA} \mathrm{cm}{ }^{-2}\right),{ }^{50} \mathrm{MnO}_{2} / / \mathrm{Fe}_{2} \mathrm{O}_{3}$ ASC $\left(0.55 \mathrm{~mW} \mathrm{~h} \mathrm{~cm}^{-3}\right.$ at $2 \mathrm{~mA}$ $\left.\mathrm{cm}^{-2}\right),{ }^{51} \mathrm{MnO}_{2}$ @CNT//PPy@CNT ASC (0.31 $\mathrm{mW} \mathrm{h} \mathrm{cm}^{-3}$ at $2 \mathrm{~mA}$ $\left.\mathrm{cm}^{-2}\right),{ }^{52} \mathrm{MnO}_{2} @ N N A / / P P y @ N N A A S C\left(1.23 \mathrm{~mW} \mathrm{~h} \mathrm{~cm}{ }^{-3}\right.$ at $1 \mathrm{~mA}$ $\left.\mathrm{cm}^{-2}\right)$, ${ }^{53} \mathrm{ZnO} @ \mathrm{MnO}_{2} / / \mathrm{RGO} \mathrm{ASC}\left(0.234 \mathrm{~mW} \mathrm{~h} \mathrm{~cm}^{-3}\right.$ at $2 \mathrm{~mA}$ $\left.\mathrm{cm}^{-2}\right),{ }^{54}$ and $\mathrm{MnO}_{2-X} / /$ RGO-ASC $\left(0.25 \mathrm{~mW} \mathrm{~h} \mathrm{~cm}^{-3}\right.$ at $2 \mathrm{~mA}$ $\left.\mathrm{cm}^{-2}\right) .{ }^{55}$ Even for a current density of $40 \mathrm{~mA} \mathrm{~cm}^{-2}$, the volumetric energy and power density of the present ASC were still as much as $2.50 \mathrm{~mW} \mathrm{~h} \mathrm{~cm}^{-3}$ and $598.85 \mathrm{~mW} \mathrm{~cm}^{-3}$, respectively. Two of the present ASCs (dimension: $1 \mathrm{~cm} \times 1 \mathrm{~cm}$ ) connected in series were used to continuously light up a 3.0 V LED lamp (Fig. S7c, $\dagger$ inset), which also demonstrates the high energy density of the as-fabricated ASC device. The above results demonstrate the very promising potential of $\mathrm{MnO}_{2}-\mathrm{MCN}$ and AC-MCN electrodes prepared using an MCN electroactive material platform for use in the development of highperformance ASC devices.

\section{Conclusions}

In summary, a method for using MCN with a 3D network "skinframework" structure as the platform of the electroactive materials of high-performance $\mathrm{MnO}_{2}-\mathrm{MCN}$ and AC-MCN 3D electrodes was proposed in this work. Compared with conventional methods such as the use of CVD and hydrothermal reaction, the proposed method is simple, involves mild reaction conditions, effective, inexpensive, and scalable. Benefiting from the unique 3D "skin-framework" architecture of MCN, the obtained electrodes offer the following advantages: (1) superb electrical conductivity and rapid electrolyte diffusion and (2) stable "skin" and large interfacial contact area, which provide a convenient and effective platform for the electroactive materials. In addition, the as-obtained $\mathrm{MnO}_{2}-\mathrm{MCN}$ anode and $\mathrm{AC}$ MCN cathode exhibit high areal capacities and excellent electrical conductivities and rate performance. The $\mathrm{MnO}_{2}-\mathrm{MCN}$ and AC-MCN electrodes exhibited capacitances of 1784.8 and 868.8 $\mathrm{mF} \mathrm{cm}{ }^{-2}$, respectively, for a current density of $5 \mathrm{~mA} \mathrm{~cm}^{-2}$. A 1.8 V solid-state ASC assembled using the electrodes also exhibited a very high volumetric capacity of $9.83 \mathrm{~F} \mathrm{~cm}^{-3}$ and maximum energy density of $4.25 \mathrm{~mW} \mathrm{~h} \mathrm{~cm}^{-3}$. These findings confirm the very high potential of using electrodes based on MCN platforms for the development of high-energy ASCs for portable electronics.

\section{Conflicts of interest}

There are no conflicts to declare.

\section{Acknowledgements}

L. Y. Xia and S. H. Hu contributed equally to this work. The authors are grateful for the support of the National Natural Science Foundation of China (31530009, 31200438), National
Key R\&D Program of China (2017YFD0600804), Hunan Provincial Natural Science Foundation of China (2015JJ2199).

\section{Notes and references}

1 L. Dong, C. Xu, Y. Li, Z. Pan, G. Liang, E. Zhou, F. Kang and Q. H. Yang, Adv. Mater., 2016, 28, 9313-9319.

2 L. Dong, C. Xu, Y. Li, C. Wu, B. Jiang, Q. Yang, E. Zhou, F. Kang and Q. H. Yang, Adv. Mater., 2016, 28, 1675-1681.

3 Z. S. Wu, K. Parvez, S. Li, S. Yang, Z. Liu, S. Liu, X. Feng and K. Mullen, Adv. Mater., 2015, 27, 4054-4061.

4 X. Wang, X. Lu, B. Liu, D. Chen, Y. Tong and G. Shen, Adv. Mater., 2014, 26, 4763-4782.

5 H. Wu, Y. Huang, F. Xu, Y. Duan and Z. Yin, Adv. Mater., 2016, 28, 9881-9919.

6 L. Wen, F. Li and H. M. Cheng, Adv. Mater., 2016, 28, 43064337.

7 S. Liu, Y. Yin, K. S. Hui, K. N. Hui, S. C. Lee and S. C. Jun, $A d v$. Sci., 2018, 5, 1800733.

8 D. Ghosh, J. Lim, R. Narayan and S. O. Kim, ACS Appl. Mater. Interfaces, 2016, 8, 22253-22260.

9 D. Yu, K. Goh, Q. Zhang, L. Wei, H. Wang, W. Jiang and Y. Chen, Adv. Mater., 2014, 26, 6790-6797.

10 K. P. Annamalai, L. Liu and Y. Tao, Adv. Mater. Interfaces, 2017, 4, 1700219.

11 P. Wu, S. Cheng, M. Yao, L. Yang, Y. Zhu, P. Liu, O. Xing, J. Zhou, M. Wang, H. Luo and M. Liu, Adv. Funct. Mater., 2017, 27, 1702160.

12 X. Lu, M. Yu, G. Wang, Y. Tong and Y. Li, Energy Environ. Sci., 2014, 7, 2160-2181.

13 J.-X. Feng, S.-H. Ye, X.-F. Lu, Y.-X. Tong and G.-R. Li, ACS Appl. Mater. Interfaces, 2015, 7, 11444-11451.

14 C. Yang, J. Shen, C. Wang, H. Fei, H. Bao and G. Wang, J. Mater. Chem. A, 2014, 2, 1458-1464.

15 A. Bora, K. Mohan, S. Doley and S. K. Dolui, ACS Appl. Mater. Interfaces, 2018, 10, 7996-8009.

16 Z. Gao, W. Yang, J. Wang, N. Song and X. Li, Nano Energy, 2015, 13, 306-317.

17 Z. Pan, Y. Qiu, J. Yang, F. Ye, Y. Xu, X. Zhang, M. Liu and Y. Zhang, Nano Energy, 2016, 26, 610-619.

18 L. Wang, H. Yang, X. Liu, R. Zeng, M. Li, Y. Huang and X. Hu, Angew. Chem., Int. Ed., 2017, 56, 1105-1110.

19 F. Zhang, T. Zhang, X. Yang, L. Zhang, K. Leng, Y. Huang and Y. Chen, Energy Environ. Sci., 2013, 6, 1623-1632.

20 T. T. Nguyen, J. Balamurugan, N. H. Kim and J. H. Lee, J. Mater. Chem. A, 2018, 6, 8669-8681.

21 K. Ghosh, C. Y. Yue, M. M. Sk and R. K. Jena, ACS Appl. Mater. Interfaces, 2017, 9, 15350-15363.

22 Y. Yang, G. Ruan, C. Xiang, G. Wang and J. M. Tour, J. Am. Chem. Soc., 2014, 136, 6187-6190.

23 Y. Shao, M. F. El-Kady, C.-W. Lin, G. Zhu, K. L. Marsh, J. Y. Hwang, Q. Zhang, Y. Li, H. Wang and R. B. Kaner, Adv. Mater., 2016, 28, 6719-6726.

24 L. Xia, X. Li, X. Wu, L. Huang, Y. Liao, Y. Qing, Y. Wu and X. Lu, J. Mater. Chem. A, 2018, 6, 17378-17388.

25 X. Yang, Z. Lin, J. Zheng, Y. Huang, B. Chen, Y. Mai and X. Feng, Nanoscale, 2016, 8, 8650-8657. 
26 H. Jiang, X. Cai, Y. Qian, C. Zhang, L. Zhou, W. Liu, B. Li, L. Lai and W. Huang, J. Mater. Chem. A, 2017, 5, 2372723736.

27 G. Zhou, L. Li, C. Ma, S. Wang, Y. Shi, N. Koratkar, W. Ren, F. Li and H.-M. Cheng, Nano Energy, 2015, 11, 356-365.

28 Y. He, W. Chen, X. Li, Z. Zhang, J. Fu, C. Zhao and E. Xie, ACS Nano, 2013, 7, 174-182.

29 V. H. Nguyen and J.-J. Shim, J. Power Sources, 2015, 273, 110117.

30 C. Wu, J. Cai, Q. Zhang, X. Zhou, Y. Zhu, P. K. Shen and K. Zhang, ACS Appl. Mater. Interfaces, 2015, 7, 26512-26521.

31 J. Wang, D. Chao, J. Liu, L. Li, L. Lai, J. Lin and Z. Shen, Nano Energy, 2014, 7, 151-160.

32 D. Kong, C. Cheng, Y. Wang, J. I. Wong, Y. Yang and H. Y. Yang, J. Mater. Chem. A, 2015, 3, 16150-16161.

33 H. Huang, Y. Tang, L. Xu, S. Tang and Y. Du, ACS Appl. Mater. Interfaces, 2014, 6, 10248-10257.

34 X. Xiong, D. Ding, D. Chen, G. Waller, Y. Bu, Z. Wang and M. Liu, Nano Energy, 2015, 11, 154-161.

35 K. Xu, W. Li, Q. Liu, B. Li, X. Liu, L. An, Z. Chen, R. Zou and J. Hu, J. Mater. Chem. A, 2014, 2, 4795-4802.

36 C. Zhou, Y. Zhang, Y. Li and J. Liu, Nano Lett., 2013, 13, 20782085.

37 G. Zhu, Z. He, J. Chen, J. Zhao, X. Feng, Y. Ma, Q. Fan, L. Wang and W. Huang, Nanoscale, 2014, 6, 1079-1085.

38 R. T. Vinny, K. Chaitra, K. Venkatesh, N. Nagaraju and N. Kathyayini, J. Power Sources, 2016, 309, 212-220.

39 K. Liang, T. Gu, Z. Cao, X. Tang, W. Hu and B. Wei, Nano Energy, 2014, 9, 245-251.

40 J.-G. Wang, F. Kang and B. Wei, Prog. Mater. Sci., 2015, 74, 51-124.
41 N. Lavoine and L. Bergström, J. Mater. Chem. A, 2017, 5, 16105-16117.

42 L. Xia, X. Li, Y. Wu and M. Rong, ACS Sustainable Chem. Eng., 2015, 3, 1724-1731.

43 L. Xia, X. Li, F. Zhu, S. Hu and L. Huang, J. Phys. Chem. C, 2017, 121, 20279-20286.

44 S. Zhu, L. Li, J. Liu, H. Wang, T. Wang, Y. Zhang, L. Zhang, R. S. Ruoff and F. Dong, ACS Nano, 2018, 12, 1033-1042.

45 Z. Zhang, F. Xiao, L. Qian, J. Xiao, S. Wang and Y. Liu, Adv. Energy Mater., 2014, 4, 1400064.

46 Y. Cheng, S. Lu, H. Zhang, C. V. Varanasi and J. Liu, Nano Lett., 2012, 12, 4206-4211.

47 Z. Pan, M. Liu, J. Yang, Y. Qiu, W. Li, Y. Xu, X. Zhang and Y. Zhang, Adv. Funct. Mater., 2017, 27, 1701122.

48 J.-X. Feng, S.-H. Ye, A.-L. Wang, X.-F. Lu, Y.-X. Tong and G.-R. Li, Adv. Funct. Mater., 2014, 24, 7093-7101.

49 L. Zhang, P. Zhu, F. Zhou, W. Zeng, H. Su, G. Li, J. Gao, R. Sun and C. P. Wong, ACS Nano, 2016, 10, 1273-1282.

50 C. Xu, Z. Li, C. Yang, P. Zou, B. Xie, Z. Lin, Z. Zhang, B. Li, F. Kang and C. P. Wong, Adv. Mater., 2016, 28, 4105-4110.

51 Y. Zeng, Y. Han, Y. Zhao, Y. Zeng, M. Yu, Y. Liu, H. Tang, Y. Tong and X. Lu, Adv. Energy Mater., 2015, 5, 1402176.

52 P. Yang, Y. Ding, Z. Lin, Z. Chen, Y. Li, P. Qiang, M. Ebrahimi, W. Mai, C. P. Wong and Z. L. Wang, Nano Lett., 2014, 14, 731-736.

53 Q. Tang, M. Chen, C. Yang, W. Wang, H. Bao and G. Wang, ACS Appl. Mater. Interfaces, 2015, 7, 15303-15313.

54 W. Zilong, Z. Zhu, J. Qiu and S. Yang, J. Mater. Chem. C, 2014, 2, 1331-1336.

55 T. Zhai, S. Xie, M. Yu, P. Fang, C. Liang, X. Lu and Y. Tong, Nano Energy, 2014, 8, 255-263. 